Cinémas

Revue d'études cinématographiques

Journal of Film Studies

\title{
Hommage au fondateur de la revue
}

\section{André Gaudreault}

Volume 19, numéro 1, automne 2008

Les transformations du cinéma

URI : https://id.erudit.org/iderudit/029495ar

DOI : https://doi.org/10.7202/029495ar

Aller au sommaire du numéro

Éditeur(s)

Cinémas

ISSN

1181-6945 (imprimé)

1705-6500 (numérique)

Découvrir la revue

Citer ce document

Gaudreault, A. (2008). Hommage au fondateur de la revue. Cinémas, 19(1), 7-9.

https://doi.org/10.7202/029495ar d'utilisation que vous pouvez consulter en ligne.

https://apropos.erudit.org/fr/usagers/politique-dutilisation/ 


\section{Hommage au fondateur de la revue}

On pourra le constater à la lecture du présent numéro, Michel Larouche a contribué au développement des études cinématographiques de façon exemplaire et novatrice. Comme le responsable du présent numéro, Serge Cardinal, en fait la démonstration, Michel Larouche a été une figure marquante en la matière. L'un de ses apports, et non le moindre, aura été la fondation (en collaboration avec Denise Pérusse) de la revue Cinémas, qui en est maintenant à sa $19^{\mathrm{e}}$ année d'existence. Cette revue, dont j'assure les destinées depuis que mon collègue m’en a confié la direction (1999), est un lieu privilégié de diffusion de la recherche en études cinématographiques. Elle a publié à ce jour 54 numéros contenant les textes de près de 250 chercheurs universitaires en provenance, principalement, du Québec, du Canada, des États-Unis et d'Europe. Face au développement rapide de la discipline et à la création, dans les années 1980, de plusieurs programmes en cinéma, dans les universités québécoises notamment, la création de la revue au début des années 1990 venait répondre à un besoin qui commençait à se faire grandissant. Du coup, la création même de la revue $\mathrm{a}$, à son tour, contribué à donner un nouveau souffle à la recherche.

Durant les dix années (1990-1999) au cours desquelles Michel Larouche a dirigé la revue, Cinémas a publié près d'une trentaine de numéros, qui portent tous, peu ou prou, son empreinte. Certains numéros thématiques traitent des sujets particulièrement novateurs (ainsi n'était-il pas évident de publier, dès 1991, un numéro intitulé "Nouvelles technologies: nouveau cinéma?", un thème dont Michel Larouche s'était fait le porteur et le défenseur). On doit aussi à sa vision pionnière d'avoir favorisé la parution de numéros sur des sujets qui paraissaient, du moins à l'époque, loin d'être évidents pour une revue savante (ainsi en est-il, par exemple, de ces deux numéros portant sur le scénario: en 1991, "Le scénario», et, en 1999, "Les scénarios 
fictifs»). Il fallait aussi être à l'écoute de ce qui se tramait dans le "milieu " pour avoir comme projet de publier, aussi tôt qu'en 1993, un numéro relativement difficile comme "Le nouveau cinéma chinois", à une époque où tout n'était pas encore joué pour ce "cinéma national» (un concept qui était d'ailleurs cher à Michel Larouche et qui l'a amené à se pencher, de façon exemplaire, sur la question de la réception du cinéma québécois à l'étranger). Plusieurs autres thèmes que Michel Larouche a privilégiés durant son mandat à la direction de la revue sont la preuve de sa grande ouverture d'esprit. En effet, l'ensemble des numéros qui ont été publiés par lui montre à l'envi que la politique de Michel Larouche par rapport aux études cinématographiques était une politique, non pas de repli sur soi, mais d'ouverture aux autres champs disciplinaires. C'est là l'une des caractéristiques essentielles de l'engagement de Michel Larouche.

Cinémas est l'une des rares revues savantes au monde à publier sur une base régulière en français et en anglais dans le champ des études cinématographiques. Elle s’est donné comme mandat de soutenir et de stimuler la recherche de pointe dans cette "discipline». Bien que la revue reste relativement accessible à tous les passionnés de cinéma, elle s'adresse essentiellement aux chercheurs et étudiants. Les objectifs de la revue sont restés les mêmes que ceux que Michel Larouche avait fixés à l'origine: 1) elle se veut un lieu de débat et de réflexion pour les chercheurs (la revue espérant ainsi témoigner de la diversité et de la vitalité de la discipline) ; 2) elle veut refléter et encourager les nouvelles approches théoriques et nouveaux courants de pensée (la revue portant une attention soutenue aux mutations de la discipline et se voulant une tribune de choix pour les jeunes chercheurs) ; 3) elle tient à participer à l'émergence de nouveaux objets d'étude (la revue témoignant un intérêt particulier envers les rapports du cinéma avec les autres médias et pratiques culturelles et encourageant la redécouverte de cinématographies et de corpus peu étudiés). Ceux qui ont connu Michel Larouche diront que pareil programme lui ressemble à s'y méprendre, car ce qu'a fait Michel, tout au long de sa carrière, c'est de répondre aux mêmes impératifs que ceux qu'il avait établis pour la revue. 
Nous ne pouvons que l'en remercier et lui tirer notre chapeau pour le saluer, bien bas.

André Gaudreault, directeur de la revue 